\title{
Hydrogen Bond Stability of Quinazoline Derivatives Compounds in Complex against EGFR using Molecular Dynamics Simulation
}

\author{
Herlina Rasyid', Bambang Purwono², Thomas S. Hofer ${ }^{3}$, and Harno Dwi Pranowo, ${ }^{1, *}$ \\ ${ }^{1}$ Austrian-Indonesian Centre (AIC) for Computational Chemistry, Faculty of Mathematics and Natural Sciences, \\ Universitas Gadjah Mada, Sekip Utara, Yogyakarta 55281, Indonesia \\ ${ }^{2}$ Department of Chemistry, Faculty of Mathematics and Natural Sciences, Universitas Gadjah Mada, \\ Sekip Utara, Yogyakarta 55281, Indonesia \\ ${ }^{3}$ Theoretical Chemistry Division, Institute of General, Inorganic and Theoretical Chemistry, University of Innsbruck, \\ Innrain 52, 6020 Innsbruck, Austria
}

* Corresponding author:

email: harnodp@ugm.ac.id

Received: October 10, 2018

Accepted: December 6, 2018

DOI: $10.22146 /$ ijc.39567

\begin{abstract}
Lung cancer was a second common cancer case due to the high cigarette smoking activity both in men and women. One of protein receptor which plays an important role in the growth of the tumor is Epidermal Growth Factor Receptor (EGFR). EGFR protein is the most frequent protein mutation in cancer and promising target to inhibit the cancer growth. In this work, the stability of the hydrogen bond as the main interaction in the inhibition mechanism of cancer will be evaluated using molecular dynamics simulation. There were two compounds (A1 and A2) as new potential inhibitors that were complexed against the EGFR protein. The dynamic properties of each complexed were compared with respect to erlotinib against EGFR. The result revealed that both compounds had an interaction in the main catalytic area of protein receptor which is at methionine residue. Inhibitor A1 showed additional interactions during simulation time, but the interactions tend to be weak. Inhibitor A2 displayed a more stable interaction. Following dynamics simulation, binding free energy calculation was performed by two scoring techniques $M M / G B(P B) S A$ method and gave a good correlation with the stability of the complex. Furthermore, potential inhibitor A2 had a lower binding free energy as a direct consequence of the stability of hydrogen bond interaction.
\end{abstract}

Keywords: hydrogen bond; quinazoline; $M D$ simulations; $M M / G B(P B) S A$

\section{- INTRODUCTION}

Tyrosine kinase receptor had been a central target on cancer therapy. This protein receptor contained an amino-terminal extracellular ligand-binding domain, hydrophobic transmembrane helix, and a cytoplasmic domain [1]. Epidermal Growth Factor Receptor (EGFR) is a member of the protein receptor of tyrosine kinase family [2]. Expression of EGFR had a correlation in tumor growth including proliferation, angiogenesis, invasion/ metastasis, and inhibition of apoptosis [3]. Strategies to blockade EGFR pathway had been developed to inhibit the progression of the tumor. The use of small molecule tyrosine kinase inhibitor is one of the strategies to inhibit the EGFR expression. This type of inhibitor act in the intracellular domain of the receptor and compete with adenosine triphosphate by the formation of a hydrogen bond and through hydrophobic interaction of ATP binding site domain of EGFR [4].

Most cases of EGFR inhibitors form several hydrogen bonds and hydrophobic interactions. Erlotinib as the first generation inhibitor exhibited a hydrogen bond with Met769 residue when complexes with EGFR wild-type [5]. Afatinib was the second generation inhibitor also form interaction with Met793 residue and hydrophobic interaction in Cys797A, Ala743A, and Leu718A [6]. Correlation between hydrogen bond and anticancer profile had been investigated in tetrazole 
analogs and found that there was an enhancing activity if the ring $\mathrm{B}$ of tetrazole substitute with hydrogen-bonding donor groups [7].

Since the crystal form of erlotinib and EGFR wildtype complex had been analyzed, we can determine the critical amino acid residue which interacts with ligand inhibitor [5]. The complex of erlotinib against EGFR frequently used in docking method to study inhibition mechanism of quinazoline derivatives. Molecular docking became an appropriate way of the computational method in drug discovery. One of the limitations of the docking method in computational drug design is only attached a static snapshot of the ligand-protein complexes [8-10]. Several studies proposed to use molecular dynamics simulation (MD) in understanding the dynamic properties of the ligand-protein complex under physiological condition [11-12].

Molecular dynamics simulation can be used to evaluate the solvent effects in docked complexes and account for induced fit, to calculate the free binding energies, and to find the binding site and correctly dock the ligand [13]. Binding free energies will be performed using the molecular mechanics/Poisson-Boltzmann surface area (MM/PBSA) and molecular mechanics/GeneralizedBorn surface area (MM/GBSA) methodology to produce a compatible result. Furthermore, this study gave a new potential of EGFR inhibitor that had been analyzing computationally and could be as a reference for the researcher to synthesis.

\section{- COMPUTATIONAL METHODS}

\section{Materials}

Complex erlotinib against EGFR (PDB ID: 1M17) and two compounds resulted from our previous study [14].

\section{Instrumentation}

This study used a PC Intel Xeon E3 1231-V3 3,4GHz, RAM 16 GB. The program used AmberTools16 [15] and VMD 1.9.2 [16].

\section{Procedure}

\section{Protein and inhibitor preparation}

There were two inhibitors was build and optimized using Density Functional Theory (DFT) method with 6-
$31 \mathrm{G}$ basis set by employing the Becke three-parameters Lee-Yang-Parr (B3LYP) functional hybrid using Gaussian 09 software [17]. Structures of these two inhibitors were shown in Fig. 1. Crystal structure of EGFR protein was gained from PDB file with PDB ID $1 \mathrm{M} 17$ and cleaned from all residues. Then, hydrogen of protein was added and charged in Chimera software package [18].

\section{Ligand docking against EGFR wild-type}

Details of ligand docking preparation had been given previously [19]. Briefly, all ligand was docked in EGFR wild-type protein and then ranked according to the binding energy value. There were 10 conformations resulted in each docking step. The chosen conformation is if there was an interaction with critical amino acid residue (Met769) by forming a hydrogen bond. These two inhibitors exhibited interaction in the catalytic domain of EGFR and the interactions stability will be evaluated by molecular dynamics simulation.

\section{Molecular dynamics simulation setup}

Protein-ligand complexes resulted from molecular docking was proceeded to molecular dynamics simulation using AmberTools16 software package applying the ff14SB force field [20]. The complexes charges and other parameters were obtained by using the general AMBER force field (GAFF) [21]. The complex then solvated with a box of TIP3P water [22] with a buffer size $15 \AA$ and neutralized by counterions. Each system was minimized in four consecutive steps. Each step for 1000 steepest descent minimization followed by 4000 steps conjugate gradient and constrained by force constant $100 \mathrm{kcal} / \mathrm{mol}$ $\AA^{-2}, 50,5$, and 0 (no constraint) which totalizing in 20.000 steps. The system then heated from $0 \mathrm{~K}$ in which every $50 \mathrm{~K}$ the temperature will be rise until $300 \mathrm{~K}$ with a time step of $1 \mathrm{fs}$, applying NVT ensemble. Then, 500 ps
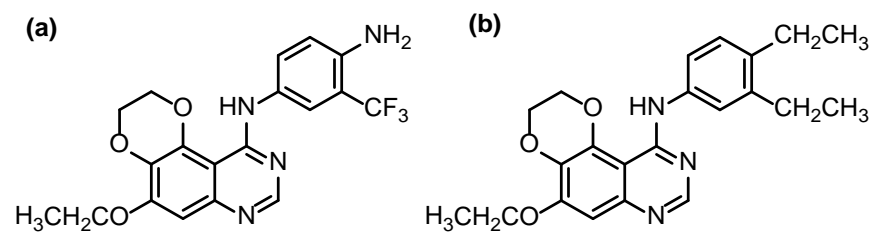

Fig 1. Structure of the two inhibitors (a) inhibitor A1, (b) inhibitor A2 
simulation in NPT ensemble was performed to equilibrate the system density while applying a time step of $2 \mathrm{fs}$. The temperature controlled using Langevin dynamics with a collision frequency of $1 \mathrm{ps}^{-1}$ and maintained at $300 \mathrm{~K}$. The pressure was fixed at 1 bar by applying a Berendsen barostat. Each system then subjected to a 500 ps "warming up" simulation in NPT ensemble. Followed by production data of simulation of $2 \mathrm{~ns}$ in total, applying NPT ensemble at $300 \mathrm{~K}$ and a time step of $0.2 \mathrm{fs}$ (10000000 steps). Longrange electrostatics are computed using the Particle Mesh Ewald (PME) with a non-bonded cut-off of $12 \AA$. The edge effect was removed by applying periodic boundary conditions. Rescoring of complexes was done by applying AMBER/GBSA and AMBER/PBSA module in AMBER15. Every second frame of production data was selected and utilized. Snapshot of data production was shown using the VMD software package.

\section{- RESULTS AND DISCUSSION}

Domain structure of EGFR kinase had a characteristic which was adopted bilobate-fold. There were two lobes on its domain (Fig. 2). The $\mathrm{NH}_{2}$-terminal (N-lobe) was formed by $\beta$-sheets and one $\alpha$-helix, whereas the $\mathrm{COOH}$ terminal (C-lobe) mostly contained $\alpha$-helix. The ATP, ATP analogs, and ATP-competitive inhibitor could be found to bind in a cleft which separated the two terminal lobes. The cleft divided into four segments which are the hinge residue, the catalytic site, the activation loop, and the kinase specificity pocket.

Erlotinib as the first generation of EGFR inhibitor had a specific interaction in EGFR domain. The N-1 and

(a)

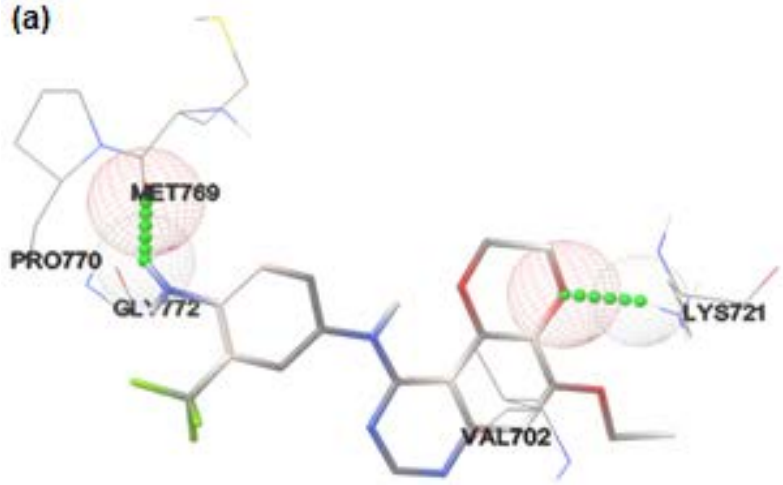

C-8 atom of quinazoline were connecting $\mathrm{N}$ - and Clobes. The $\mathrm{N} 1$ atom accepted a hydrogen bond from Met769 amide nitrogen. The N3 atom has a hydrogen bond interaction with Thr766 side chain mediated from water molecule as a bridge [5]. However, this water molecule did not give any essential effect on the inhibitory process [23]. Binding mode of EGFR inhibitor was driven by a strong hydrogen bond with a methionine residue at the hinge domain through the $\mathrm{N} 1$ atom of quinazoline ring.

\section{Molecular Docking}

Both of ligand (A1 and A2) resulted by QSAR analysis from our previous study [14], then continue to

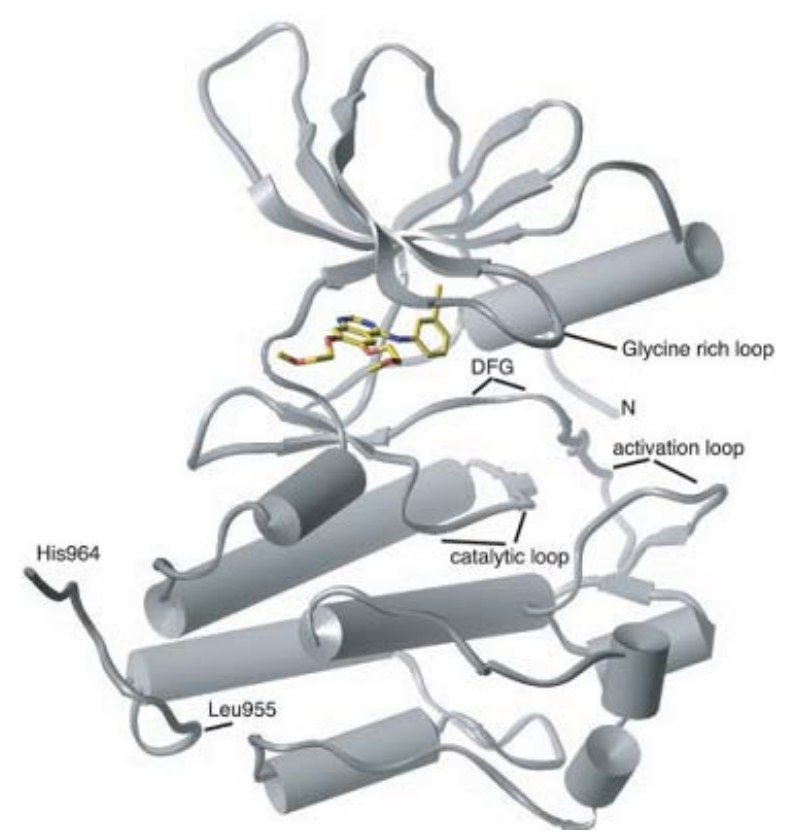

Fig 2. Structural of EGFR protein [5]

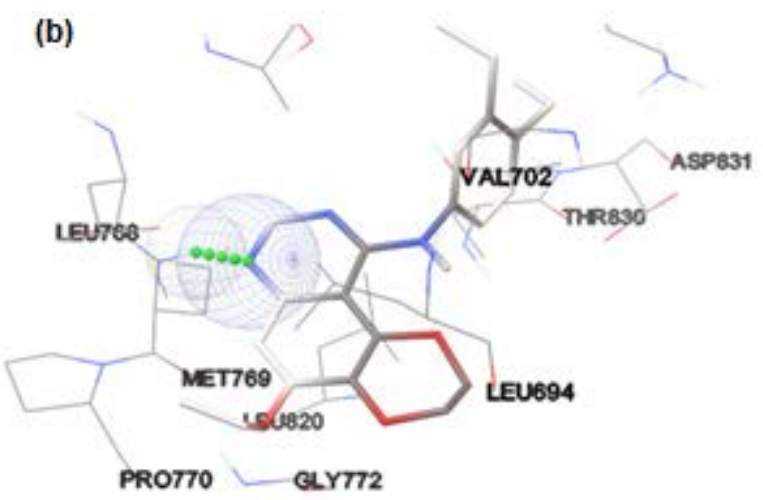

Fig 3. Interaction ligand (a) A1 and (b) A2 against EGFR 
find the interaction between EGFR protein used molecular docking. Binding region of both inhibitors showed the same interaction located in the hinge region of EGFR. Fig. 3 presented the result of docking studies from two inhibitors against EGFR protein. Both inhibitors showed an interaction in the main catalytic area that was Met769, and there is an additional interaction in the other amino acid residue. Several studies have shown that quinazoline derivative compound such as erlotinib, afatinib, lapatinib, bind to amino acid residue Met769 or Met793 [24-26].

\section{Stability Analysis}

In order to probe the dynamic stability of the two inhibitors, root means square displacement (RMSD) and root mean square fluctuation (RMSF) values were calculated and plotted. Fig. 4 displayed comparison of RMSD and RMSF plot for each inhibitor in complex with EGFR protein. Complex inhibitor A2 against EGFR
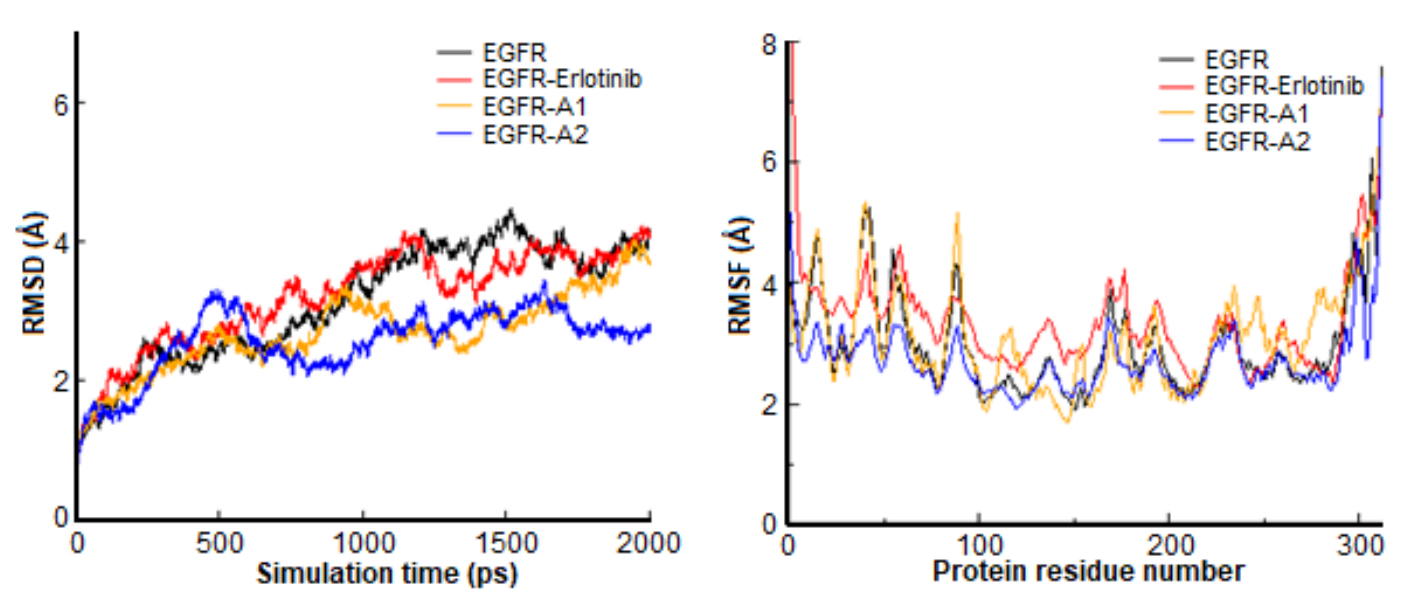

Fig 4. RMSD and RMSF plot of complex inhibitors and EGFR protein
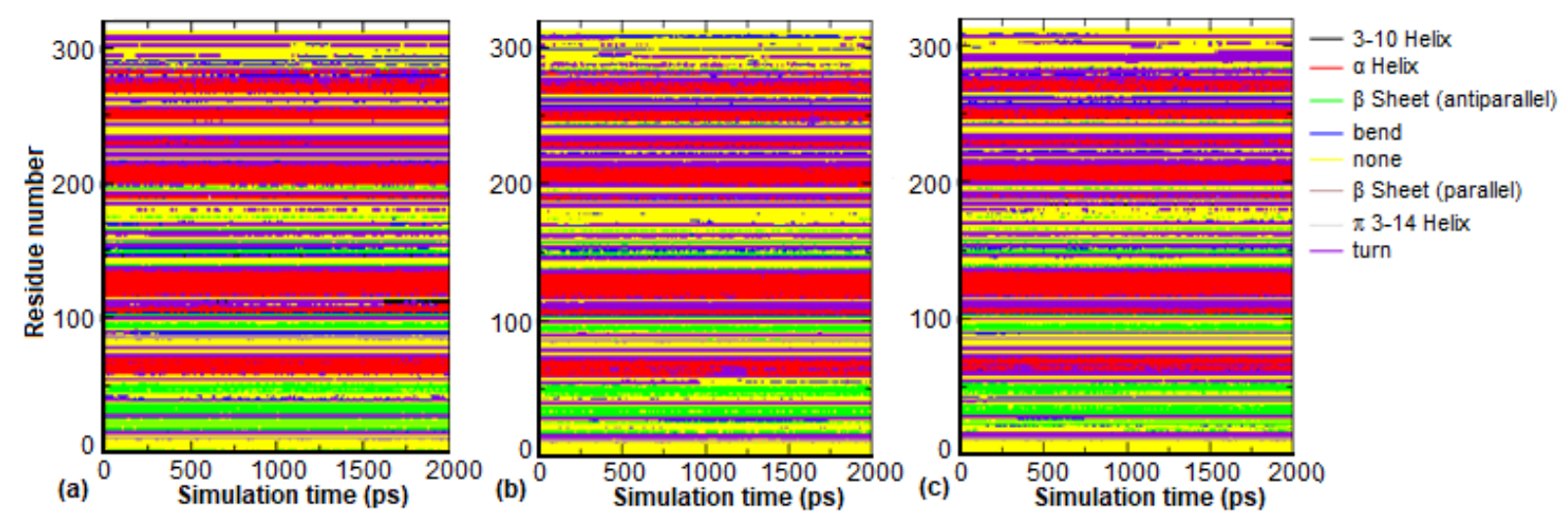

Fig 5. DSSP plot of complex EGFR with (a) EGFR, (b) EGFR-A1, and (c) EGFR-A2 showed a more stable complex structure than the others. Addition of inhibitor A2 into the active site of EGFR made the RMSD value of EGFR decreasing more than the presence of erlotinib or inhibitor A1. This is also supported from RMSF analysis that showed that EGFRA2 complex had a relatively smaller fluctuation in comparison to the other complexes and fluctuation pattern of EGFR-A2 complex and empty EGFR had a similar pattern indicating that the presence of inhibitor A2 did not affect the overall structure but made a more stable complex due to a lower fluctuation.

\section{Define Secondary Structure Protein (DSSP) Analysis}

DSSP analysis was conducted to get more specific information for each complex in time series. Fig. 5 showed the DSSP plot for each complex compared to DSSP plot of empty EGFR. All of the complexes showed domination of alpha helix motif. Analysis DSSP of both 
EGFR-A1 and EGFR-A2 complexes showed a modification from $a$ helix to turn motif whereas empty EGFR did not give any modification in residue number around 60-75. This alteration could happen because both ligands (A1 and A2) formed a more stable structure to the EGFR than the empty structure of EGFR. This finding also supported by the RMSF result which showed that residue number fluctuation of EGFR-A1 and EGFR-A2 complexes were relatively lower than the empty EGFR. The other alteration was around residue number 110-115, there was a change of motif from turn to 3-10 helix of EGFR whereas complex EGFR-A1 and EGFR-A2 did not have any modification. This phenomenon could be caused by the presence of ligand A1 or A2 in the structure of EGFR protein.

\section{Binding Mode of Inhibitor A1}

Analysis of total hydrogen bond had been conducted to the inhibitor A1 during simulation time. Fig. 6 presented the total of hydrogen bond interactions during 2000 ps. There were 4 amino acid residues that always appeared since the beginning of simulation time until 1800 ps, but at the end of simulation time, this amount reduced to two hydrogen bonds. This interaction was divided into two domains, namely hydrogen bonding interaction in the main region or conventional hinge residue and the additional residue.

\section{Binding to the Conventional Hinge Residue}

AMBER software package renumbering all of amino acid residue number of protein. Furthermore, residue number of Met769 changed to Met98 in AMBER process. Hydrogen bond interaction between inhibitor A1 and protein in the hinge residue took place in methionine residue (Met98). Interaction in this particular residue was the most important anchor and played a critical role in the inhibition properties of inhibitor $[11,27]$.

Fig. 7 showed Radial Distribution Function (RDF) graph and hydrogen bond distance of between atoms $\mathrm{N} 1$ of the ligand with hydrogen of Met98. RDF is one of the correlation functions that describe how an atom with the other atoms in a system radially surrounded each other. RDF graph described the strength of the bond and also how many atoms it surrounds. RDF analysis of ligand A1 and Met98 indicated a peak at a distance about $2.05 \AA$ which mean that during simulation time the distance

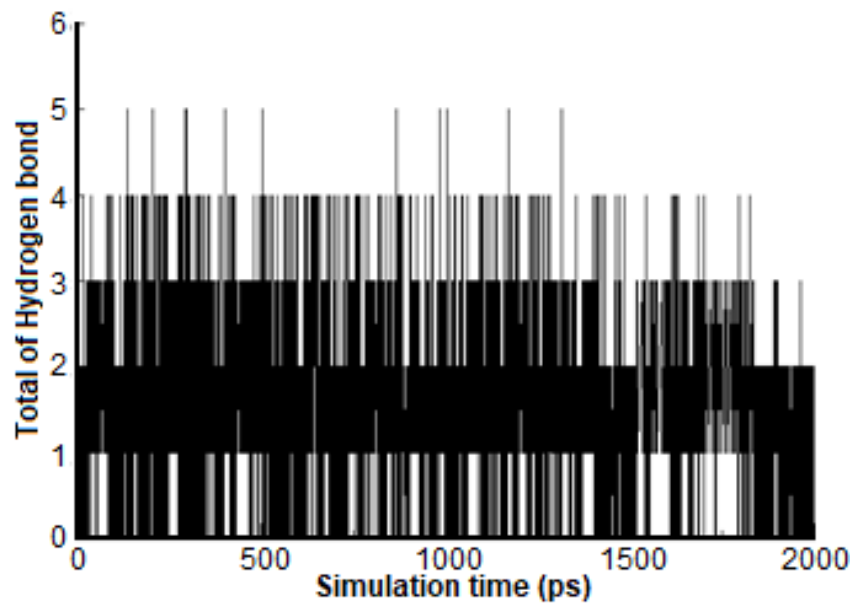

Fig 6. Total of hydrogen bonds formed by inhibitor A1 with EGFR in 2000 ps simulation time

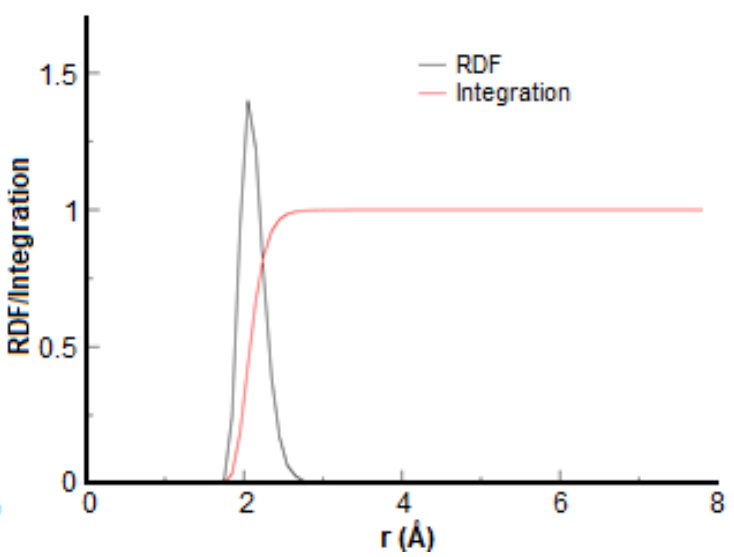

Fig 7. Hydrogen bond distance and RDF graph of inhibitor A1 with Met98 residue in 2000 ps simulation time 

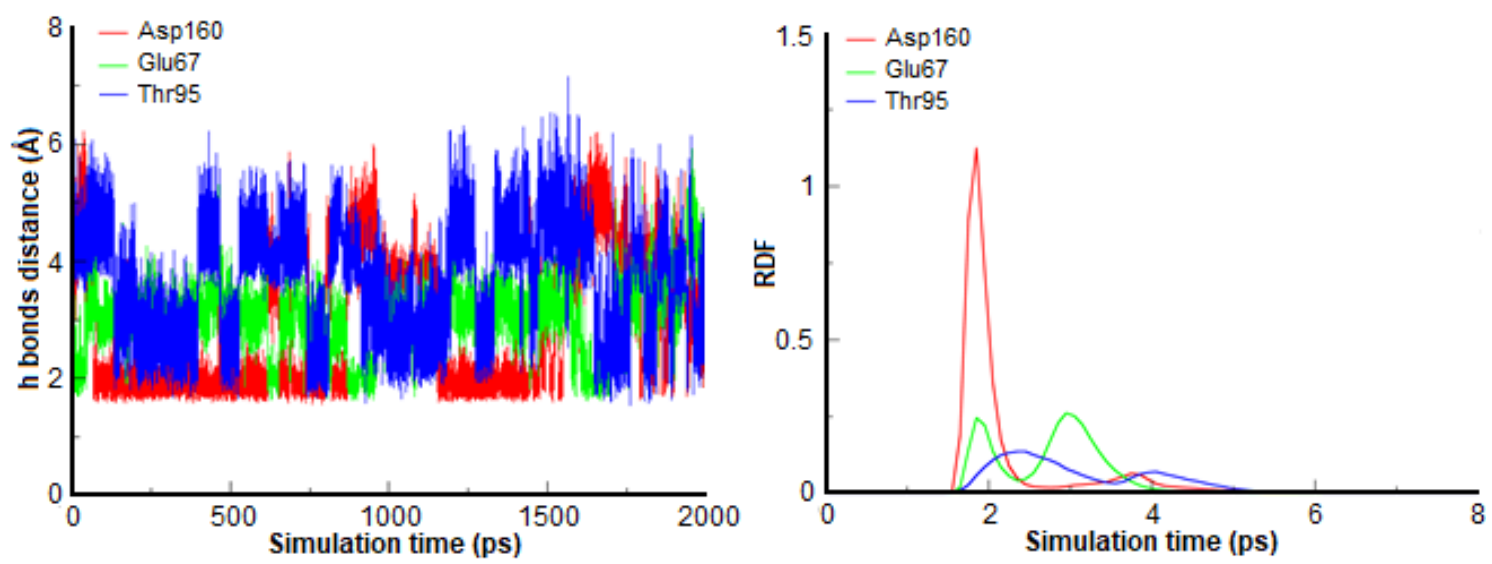

Fig 8. Hydrogen bond distance and RDF graph of additional hydrogen bond interactions
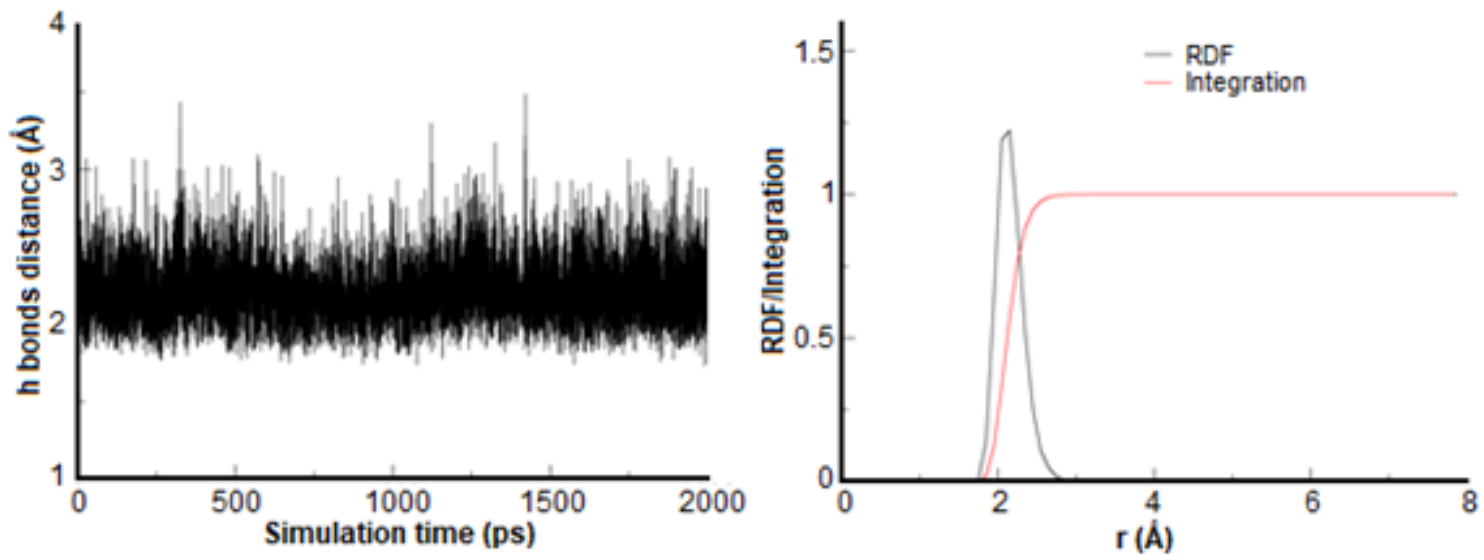

Fig 9. Hydrogen bond distance and RDF graph of inhibitor A2 against Met98

between the $\mathrm{N}$ atoms on the ligand and the $\mathrm{H}$ atoms of the Met98 tend to unchanged.

\section{Binding to the additional residue}

Interactions in the additional residues between inhibitor $\mathrm{A} 1$ and protein occurred in amino acid residue Asp160, Glu67, and Thr95. Fig. 8 represented hydrogen bond distance and RDF graph of each hydrogen bond interaction. Hydrogen bond interaction against Asp160 residue showed a strong interaction in the beginning simulation time but tend to weaken as the simulation time increases. The H16 atom formed a bond with Asp160 and sometimes changed with Glu67, that made the hydrogen bonding of the ligand and Asp160 or Glu67 tend to be weak. It could be seen from the widening shape of RDF graph. It is also supported by analysis of the hydrogen bond distance that showed a distance of about 3-4 $\AA$ which is classified as a weak hydrogen bond [28].
The third interaction in additional residue happened with atom Fluor $\left(-\mathrm{CF}_{3}\right)$ of inhibitor and Thr95 resulted in intermolecular hydrogen bond which classified as a weak hydrogen bond. The result of hydrogen bonding distance analysis was highly fluctuate, showing that these two atoms can bind and loose easily. This phenomenon can occur due to the hybridization of the carbon atom in $\left(-\mathrm{CF}_{3}\right)$ substituent in the form of tetrahedron consequently it could rotate easily and causing the weak bond to be released and reformed over the simulation.

\section{Binding mode of inhibitor A2}

Interaction of inhibitor A2 and protein EGFR only occurred in the conventional hinge residue or Met98. Fig. 9 displayed inhibitor interaction, RDF graph, and hydrogen bond distance of atom N3 ligand and Met98. This interaction tends to be strong interaction which could 

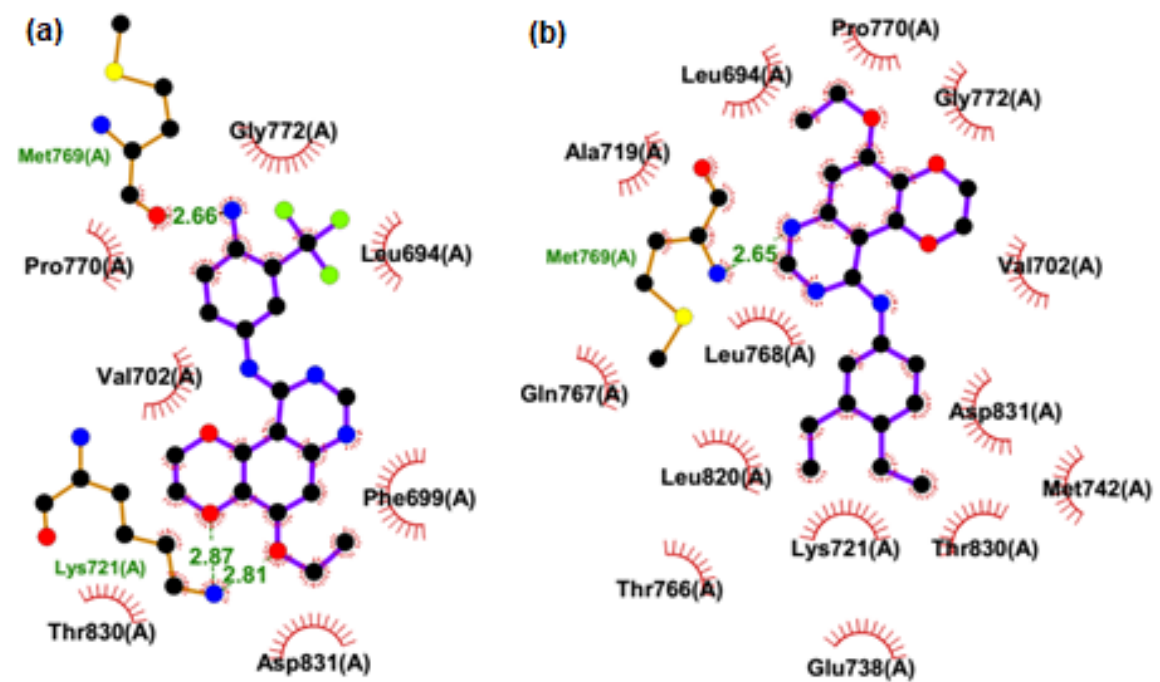

Fig 10. Hydrophobic interaction (red color) of compound (a) A1 and (b) A2 against EGFR

be seen from the shape of RDF graph as sharp. It also supported by the stability of hydrogen bond distance during simulation time without any significant fluctuations.

\section{Hydrophobic Interaction}

Hydrophobic interaction is one of the intermolecular bonding forces that have an important role in the inhibition mechanism of the drug. Fig. 10 showed hydrophobic interaction both of compound against EGFR protein and resulted that complex A2-EGFR had a more hydrophobic interaction. Erlotinib as standard ligand showed hydrophobic interaction that located in Leu820(A), Leu694(A), Gly772(A), and Leu768(A) residues [5] and complex A2-EGFR also presented similar interaction.

\section{Binding Energy Calculation}

Binding free energy $\left(\Delta \mathrm{G}_{\text {binding }}\right)$ of two complex inhibitors were calculated using the MM/PBSA and MM/GBSA procedure. Binding free energy was predicted based on the free energy of complex, protein, and inhibitor that collected from the trajectory of a complex. $\Delta \mathrm{G}_{\text {binding }}=\mathrm{G}_{\text {complex }}(\mathrm{i})-\mathrm{G}_{\text {protein }}(\mathrm{i})-\mathrm{G}_{\text {inhibitor }}(\mathrm{i})_{\mathrm{i}}$

Table 1 exhibited binding free energy of complex inhibitors. Inhibitor A2 showed better binding energy $\left(\Delta \mathrm{G}_{\text {binding }}\right)$ than inhibitor $\mathrm{A} 1$ because a more stable complex resulted during simulation time. This more stable
Table 1. Binding free energy $\Delta \mathrm{G}_{\text {binding }}$ for $\mathrm{MD}$-produced complexes $(\mathrm{kcal} / \mathrm{mol})$

\begin{tabular}{|c|c|c|c|}
\hline & erlotinib & Compound A1 & Compound A2 \\
\hline \multicolumn{4}{|c|}{ MM-GBSA method } \\
\hline vdWaals & -46.2945 & -46.8593 & -55.4868 \\
\hline EEL & -21.6860 & -29.0508 & -15.4623 \\
\hline EGB & 37.1376 & 41.7714 & 30.3694 \\
\hline ESURF & -5.6563 & -6.3003 & -6.5510 \\
\hline$\Delta G_{\text {binding }}$ & -36.4992 & -40.4390 & -47.1351 \\
\hline \multicolumn{4}{|c|}{ MM-PBSA method } \\
\hline vdWaals & -46.2945 & -46.8593 & -55.4868 \\
\hline EEL & -21.6860 & -29.0508 & -15.4623 \\
\hline EPB & 44.1457 & 47.0195 & 38.2820 \\
\hline ENPOLAR & -30.2970 & -32.2888 & -36.8300 \\
\hline EDISPER & 57.9161 & 59.6393 & 64.2669 \\
\hline$\Delta \mathrm{G}_{\text {binding }}$ & 3.7843 & -1.5400 & -5.2346 \\
\hline
\end{tabular}

complex could be caused by a more stable hydrogen bond interaction, inhibitor $\mathrm{A} 1$ had four hydrogen bond interactions but that bond tends to be weak. Whereas inhibitor A2 displayed only one hydrogen bond but this bond was a strong bond.

\section{- CONCLUSION}

Hydrogen bond stability over the two inhibitors had been investigated using molecular dynamic simulation and binding energy calculation. Both of inhibitor had an interaction in the main catalytic area (Met98 residue). Even inhibitor A1 had three other 
interactions in additional residue, but the interaction tends to be weak interaction at the end of simulation time. Stability and DSSP analysis showed that EGFR-A2 complex had a more stable complex structure than the other complexes. Both MM/PBSA and MM/GBSA rescoring methods performed well and resulted in inhibitor A2 had stronger binding energy in complex with EGFR protein than inhibitor A1.

\section{- ACKNOWLEDGMENTS}

This paper is dedicated to the memory of our respectful supervisor Dr.rer.nat. Ria Armunanto. H. Rasyid acknowledges a Ph.D scholarship issued by the Ministry of Research, Technology, and Higher Education of the Republic of Indonesia through PMDSU program as in contract number 1511/E4.4/2015.

\section{- REFERENCES}

[1] Madhusudan, S., and Ganesan, T.S., 2004, Tyrosine kinase inhibitors in cancer therapy, Clin. Biochem., 37 (7), 618-635.

[2] Vallbohmer, D., and Lenz, H.J., 2005, Epidermal growth factor receptor as a target for chemotherapy, Clin. Colorectal Cancer, 5 (Suppl. 1), S19-27.

[3] Baselga, J., 2002, Why the epidermal growth factor receptor? The rationale for cancer therapy, Oncologist, 7 (Suppl. 4), 2-8.

[4] Ismail, R.S.M., Ismail, N.S.M., Abuserii, S., and El Ella, D.A.B., 2016, Recent advances in 4aminoquinazoline based scaffold derivatives targeting EGFR kinases as anticancer agents, Future J. Pharm. Sci., 2 (1), 9-19.

[5] Stamos, J., Sliwkowski, M.X., and Eigenbrot, C., 2002, Structure of the epidermal growth factor receptor kinase domain alone and in complex with a 4-anilinoquinazoline inhibitor, J. Biol. Chem., 277 (48), 46265-46272.

[6] Solca, F., Dahl, G., Zoephel, A., Bader, G., Sanderson, M., Klein, C., Kraemer, O., Himmelsbach, F., Haaksma, E., and Adolf, G.R., 2012, Target binding properties and cellular activity of afatinib (BIBW 2992), an irreversible ErbB family blocker, $J$. Pharmacol. Exp. Ther., 343 (2), 342-350.

[7] Jedhe, G.S., Paul, D., Gonnade, R.G., Santra, M.K.,
Hamel, E., Nguyen, T.L., and Sanjayan, G.J., 2013, Correlation of hydrogen-bonding propensity and anticancer profile of tetrazole-tethered combretastatin analogues, Bioorg. Med. Chem. Lett., 23 (16), 46804684.

[8] Amin, K.M., Georgey, H.H., and Awadallah, F.M., 2011, EGFR tyrosine kinase targeted compounds: Synthesis, docking study, and in vitro antitumor activity of some new quinazoline and benzo[d]isothiazole derivatives, Med. Chem. Res., 20 (7), 1042-1053.

[9] Tu, Y., Ouyang, Y., Xu, S., Zhu, Y., Li, G., Sun, C., Zheng, P., and Zhu, W., 2016, Design, synthesis, and docking studies of afatinib analogs bearing cinnamamide moiety as potent EGFR inhibitors, Bioorg. Med. Chem., 24 (7), 1495-1503.

[10] Lü, S., Zheng, W., Ji, L., Luo, Q., Hao, X., Li, X., and Wang, F., 2013, Synthesis, characterization, screening and docking analysis of 4-anilinoquinazoline derivatives as tyrosine kinase inhibitors, Eur. J. Med. Chem., 61, 84-94.

[11] Ahmed, M., Sadek, M.M., Abouzid, K.A., and Wang, F., 2013, In silico design: Extended molecular dynamic simulations of a new series of dually acting inhibitors against EGFR and HER2, J. Mol. Graphics Modell., 44, 220-231.

[12] Ahmed, M., Sadek, M.M., Serrya, R.A., Kafafy, A.H.N., Abouzid, K.A., and Wang, F., 2013, Assessment of new anti-HER2 ligands using combined docking, QM/MM scoring and MD simulation, J. Mol. Graphics Modell., 40, 91-98.

[13] Alonso, H., Bliznyuk, A.A., and Gready, J.E., 2006, Combining docking and molecular dynamic simulations in drug design, Med. Res. Rev., 26 (5), 531-568.

[14] Rasyid, H., Armunanto, R., and Purwono, B., 2017, Study of quinazoline derivative compound as anticancer on $\mathrm{EGFR}^{\mathrm{WT}}$ protein using quantitative structure-activity relationship (QSAR), Int. J. Pharm. Sci. Rev. Res., 42 (1), 44-49.

[15] Case, D.A., Betz, R.M., Botello-Smith, W., Cerutti, D.S., Cheatham, T.E., Darden, T.A., Duke, R.E., Giese, T.J., Gohlke, H., Goetz, A.W., Homeyer, N., Izadi, S., Janowski, P., Kaus, J., Kovalenko, A., Lee, 
T.S., LeGrand, S., Li, P., Lin, C., Luchko, T., Luo, R., Madej, B., Mermelstein, D., Merz, K.M., Monard, G., Nguyen, H., Nguyen, H.T., Omelyan, I., Onufriev, A., Roe, D.R., Roitberg, A., Sagui, C., Simmerling, C.L., Swails, J., Walker, R.C., Wang, J., Wolf, R.M., Wu, X., Xiao, L., York, D.M., and Kollman, P.A., 2016, AMBER 2016, University of California, San Fransisco.

[16] Humprey, M.C., Dalke, A., and Schulten, K., 1996, VMD: Visual molecular dynamics, J. Mol. Graphics, 14 (1), 33-38.

[17] Frisch, M.J., Trucks, G.W., Schlegel, H.B., Scuseria, G.E., Robb, M.A., Cheeseman, J.R., Scalmani, G., Barone, V., Mennucci, B., Petersson, G.A., Nakatsuji, H., Caricato, M., Li, X., Hratchian, H.P., Izmaylov, A.F., Bloino, J., Zheng, G., Sonnenberg, J.L., Hada, M., Ehara, M., Toyota, K., Fukuda, R., Hasegawa, J., Ishida, M., Nakajima, T., Honda, Y., Kitao, O., Nakai, H., Vreven, T., Montgomery, Jr., J.A., Peralta, J.E., Ogliaro, F., Bearpark, M., Heyd, J.J., Brothers, E., Kudin, K.N., Staroverov, V.N., Kobayashi, R., Normand, J., Raghavachari, K., Rendell, A., Burant, J.C., Iyengar, S.S., Tomasi, J., Cossi, M., Rega, N., Millam, J.M., Klene, M., Knox, J.E., Cross, J.B., Bakken, V., Adamo, C., Jaramillo, J., Gomperts, R., Stratmann, R.E., Yazyev, O., Austin, A.J., Cammi, R., Pomelli, C., Ochterski, J.W., Martin, R.L., Morokuma, K., Zakrzewski, V.G., Voth, G.A., Salvador, P., Dannenberg, J.J., Dapprich, S., Daniels, A.D., Farkas, Ö., Foresman, J.B., Ortiz, J.V., Cioslowski, J., and Fox, D.J., 2009, Gaussian 09, Revision A.02, Gaussian, Inc., Wallingford CT.

[18] Pettersen, E.F., Goddard, T.D., Huang, C.C., Couch, G.S., Greenblatt, D.M., Meng, E., and Ferrin, T.E., 2004, UCSF Chimera-A visualization system for exploratory research and analysis, J. Comput. Chem., 25 (13), 1605-1612.

[19] Rasyid, H., Purwono, B., and Armunanto, R., 2017, Molecular docking analysis on epidermal growth factor receptor wild type (EGFR ${ }^{\mathrm{WT}}$ ) with quinazoline derivative compounds as tyrosine kinase inhibitors, KMUTNB Int. J. Appl. Sci. Technol., 10 (4), 293-299.

[20] Maier, J., Martinez, C., Kasavajhala, K., Wickstrom, L., Hauser, K., and Simmerling, C., 2015, ff14SB:
Improving the accuracy of protein side chain and backbone parameters from ff99SB, J. Chem. Theory Comput., 11 (8), 3696-3713.

[21] Wang, J., Wolf, R.M., Caldwell, J.W., Kollman, P.A., and Case, D.A., 2004, Development and testing of a general AMBER force field, J. Comput. Chem., 25 (9), 1157-1174.

[22] Jorgensen, W.L., Chandrasekhar, J., Madura, J.D., Impey, R.W., and Klein, M.L., 1983, Comparison of simple potential functions for simulating liquid water, J. Chem. Phys., 79, 926-935.

[23] Rewcastle, G.W., Palmer, B.D., Bridges, A.J., Showalter, H.D.H., Sun, L., Nelson, J., McMichael, A., Kraker, A.J., Fry, D.W., and Denny, W.A., 1996, Tyrosine kinase inhibitors. 9. Synthesis and evaluation of fused tricyclic quinazoline analogues as ATP site inhibitors of the tyrosine kinase activity of the epidermal growth factor receptor, J. Med. Chem., 39 (4), 918-928.

[24] Patel, H., Pawara, R., Ansari, A., and Surana, S., 2017, Recent updates on third generation EGFR inhibitors and emergence of fourth generation EGFR inhibitors to combat C797S resistance, Eur. J. Med. Chem., 142, 32-47.

[25] Wang, S., Song, Y., and Liu, D., 2017, EAI045: The fourth-generation EGFR inhibitor overcoming T790M and C797S resistance, Cancer Lett., 385, 5154.

[26] Cheng, H., Nair, S.K., and Murray, B.W., 2016, Recent progress on third generation covalent EGFR inhibitors, Bioorg. Med. Chem. Lett., 26, 1861-1868.

[27] Bridges, A.J., Zhou, H., Cody, D.R., Rewcastle, G.W., McMichael, A., Showalter, H.D.H., Fry, D.W., Kraker, A.J., and Denny, W.A, 1996, Tyrosine kinase inhibitors. 8. An unusually steep structure-activity relationship for analogues of 4(3-bromoanilino)-6,7-dimethoxyquinazoline (PD 153035), a potent inhibitor of the epidermal growth factor receptor, J. Med. Chem., 39 (1), 267-276.

[28] Jeffrey, G.A., and Saenger, W., 1991, Hydrogen Bonding in Biological Structures, $1^{\text {st }}$ ed., SpringerVerlag Berlin Heidelberg. 